\title{
INTERCULTURALIDADE, AUTODETERMINAÇÃO E CIDADANIA DOS POVOS INDÍGENAS

\author{
INTERCULTURALITY, SELF-DETERMINATION AND CITIZENSHIP OF INDIAN \\ PEOPLE
}

Saulo Tarso Rodrigues*

\begin{abstract}
El paradigma liberal se encuentra em el origen de la aversión de los estados al reconocimiento de derechos coletivos de grupos diferentes a ellos mismos. Los derechos colectivos son vistos como amenazas al principio de la soberania y combustible de las tensiones domésticas [...] Em primer lugar, a pesar del reconocimiento internacional de los derechos humanos universales como proceso civilizador, la discriminación contra los pueblos indígenas y las minorias étnicas ha sido praticada e incluso respaldada juridicamente a lo largo de los anõs [...] En segundo lugar, trás una larga historia de genocidio y etnocidio, de politicas de exclusión o integración impuestas, la eliminación no puede ser lograda a través de la mera igualdade formal frente a la ley. (Boaventura de Sousa Santos)
\end{abstract}

Resumo: O princípio da autodeterminação, baseado em uma ética global do direito à diferença, tem sido afetado por um novo interesse em identidade cultural e diferença cultural, que reflete, dessa forma, nas normas e nos sistemas institucionais surgidos a partir da afirmação das identidades específicas e, portanto, da interculturalidade. A partir da (re)conceitualização dos direitos do homem enquanto direito a se autodeterminar, os direitos humanos passaram a incorporar novos conceitos, visto que se autodeterminar exige a superação de uma cultura homogênea e, portanto, a negação de qualquer modelo cultural que vise excluir ou assimilar outras culturas e assim negar a diversidade. A luta pelos direitos coletivos dos povos indígenas deve partir primeiramente de uma política de reconhecimento e de pluralidade jurídica, entendendo como tal a obrigação dos
Estados nacionais de reconhecerem os direitos coletivos, de um lado, e, de outro, possibilitarem a criação de uma competência jurídica interna, viabilizando o desafio ao monopólio da produção e da distribuição do direito. Este artigo sustenta que a ideia de Estado pluriétnico e de cidadania multicultural foi um dos fundamentos do Estado brasileiro por meio da Constituição democrática de 1988, no qual reconheceu expressamente as diferenças étnico-culturais dos povos indígenas garantindo suas organizações sociais, usos, costumes, tradições, direito ao território e capacidade postulatória, fundamento esse, aliás, no direito expresso na Carta Magna à autodeterminação dos povos.

Palavras-chave: Autodeterminação dos povos. Direito indígena. Discriminação. Direitos humanos.

\footnotetext{
* Pós-doutor em Direito Constitucional pela Universidade de Uppsala, Suécia; Doutor em Sociologia do Estado e do Direito pela Universidade de Coimbra (UC), em Portugal; Professor Adjunto da Universidade Federal do Mato Grosso (UFMT), MT; Professor do Programa de Mestrado em Direito Agroambiental da Universidade Federal do Mato Grosso (UFMT), MT, na disciplina Direito dos povos indígenas e das comunidades tradicionais; Avenida Fernando Corrêa da Costa, 2367, Boa Esperança, 79060-900, Cuiabá, Mato Grosso, Brasil; saulorodrigues@yahoo.com.br
} 


\begin{abstract}
The principle of self-determination is based on the universal right to difference. It has been affected by a new interest in cultural identity and cultural difference, which reflects, thus, on standards and institutional systems arising from the assertion of specific identities and, therefore, interculturality. From the (re)conceptualization of human rights as the right to self-determination, human rights began to incorporate new concepts, since self-determination requires the overcoming of a homogeneous culture and, therefore, the negation of any cultural model that seeks to exclude or assimilate other cultures and thereby denying diversity. The struggle for collective rights of indigenous people should start from a politics of recognition and legal plurality. This requires the commitment of national states to recognize the collective rights of indigenous people and the possibility of a legal authority for private production and distribution law. This article argues that the idea of State multiethnic and multicultural citizenship was one of the foundations of the Brazilian State through the democratic Constitution of 1988 and that the Constitution expressly recognized the ethnic and cultural differences of indigenous peoples by ensuring their social organizations, customs, traditions, right to territory and capacity postulatória, this plea, moreover, in the right expressed in the Carta Magna to self-determination of people.
\end{abstract}

Keywords: Self-determination. Indigenous law. Discrimination. Human rights.

\title{
Introdução
}

O presente artigo científico teve como objetivo discutir as bases centrais do direito humano à autodeterminação dos povos e seus reflexos na afirmação dos povos indígenas como "sujeitos" de direitos. Partindo de uma concepção denominada por Boaventura de Sousa Santos pós-colonialista, pretendemos estabelecer um pensamento crítico para uma nova "conceitualização" teórica não mais calcada no universalismo abstrato, mas nas intersubjetividades e em uma nova cidadania, diferenciada, multicultural, dinâmica, criativa e participativa, no sentido de construir os direitos diferenciados criando contextos plurais e heterogêneos para que a convivência democrática possibilite o desenvolver das ações da vida sem opressão, sem exclusão.

O discurso dominante tanto no horizonte político quanto no econômico e jurídico, mediante uma universalização colonial, determinou a exclusão das sociedades indígenas ao longo da história, ideologizando e naturalizando as diferenças culturais, tornando-as práticas consideradas bárbaras e selvagens, discurso necessário para a implementação de um projeto econômico. No que diz respeito ao Estado brasileiro, os grupos diferenciados nos quais se incluem os povos indígenas compõem a estrutura social e cultural de nossa sociedade, no entanto, considerados paradoxalmente como sociedades culturalmente diferenciadas da nacional hegemônica, ou como uma espécie de subsociedade. Isso reflete o longo processo de colonização e de construção do Estado nacional, no qual em relação ao Estado brasileiro se promoveu genocídios e etnocídios que foram responsáveis pelo quase total extermínio de numerosas culturas e povos indígenas.

Com a promulgação da Constituição de 1988 reconhecendo expressamente as diferenças étnico-culturais que as pessoas indígenas e suas sociedades configuram, pelo reconhecimento dos índios, suas organizações sociais, usos, costumes, tradições, direito ao território e capacidade postulatória, um novo tempo de direitos se 
abre aos povos indígenas. Um novo tempo, não mais marcado pela exclusão jurídica, mas pela inclusão constitucional das pessoas e povos indígenas em suas diferenças, valores, realidades e práticas sociais.

No entanto, pode-se dizer que, para além de um processo formal de constitucionalização dos direitos indígenas, é necessária, para a efetivação de seus direitos historicamente excluídos, uma profunda revisão das bases colonialistas firmadas na ideia de homogeneização e universalização de valores considerados hegemônicos.

\section{1 princípio da autodeterminação dos povos e a ressignificação dos direitos humanos}

A ideia da autodeterminação como um direito reconhecido no âmbito da cidadania se tornou importante a partir dos recentes debates sobre ética nas relações internacionais, mais precisamente com as demandas surgidas a partir do desenvolvimento do nacionalismo no século XIX na Europa, ganhando força com as lutas pela libertação nacional no mundo colonial durante o século XXI, tendo seu ponto culminante e, portanto, ganhando relevância teórica, após o sucesso dos processos de descolonização em vários Estados da Europa (SANTOS, 2001). O direito à autodeterminação, mais do que uma discussão jurídica, constitui-se um problema também de ordem moral (DHABOUR, 1998, p. 3). Isso ocorre porque a autodeterminação é um conceito com diferentes significados, que pode ser compatível ou incompatível com correntes doutrinárias no âmbito do direito internacional, dependendo, portanto, de qual corrente é aceita (DHABOUR, 1998, p. 4).

Há, portanto, diferentes correntes de interpretação desse princípio, que podem ser definidas basicamente em três marcos teóricos. Primeiramente, significa o princípio democrático que assegura a existência de determinados indivíduos em um determinado território, tendo relevância no caso dos movimentos anticoloniais, nos quais a autodeterminação significa a prerrogativa de autogovernabilidade da população dos territórios coloniais. Em segundo, uma interpretação nacionalista da autodeterminação indica a separação da condição estatal pelos grupos nacionais, caso não seja reconhecido o direito às diferenças pelos organismos nacionais e internacionais. Por último, uma interpretação regional do princípio da autodeterminação pode ser considerada no sentido da aplicabilidade deste aos movimentos indígenas, pelo direito à autonomia cultural e, portanto, pela aplicabilidade de recursos institucionais para a preservação de suas fronteiras territoriais e de sua forma de vida (DHABOUR, 1998, p. 4).

No entanto, não é coerente buscar uma separação teórica da autodeterminação, na medida em que, se partirmos somente da primeira forma, ela seria apenas vista como um princípio democrático equivalendo à ideia de que os indivíduos têm apenas o direito de participar do processo democrático; isso exauriria a sua função. Quando visto sob o ponto de vista dos movimentos nacionalistas, o princípio nacional poderia ser a base para demandas contra Estados democráticos, na busca por 
unidades étnicas e territoriais. Por último, pensando sobre termos regionais, indica apenas um interesse na autonomia necessária para proteger indivíduos que fazem parte de uma região geográfica particular.

Contudo, a maior parte dos teóricos do âmbito das relações internacionais busca apenas uma justificação democrática para esse princípio, na qual o define apenas como o direito a participar do processo democrático, ou seja, resumindo-se única e exclusivamente no âmbito da autogovernabilidade, em que seria uma simples extensão do ato de reconhecimento de entidades políticas como autogovernáveis (DHABOUR, 1998, p. 3). Isso demonstra a variante do clássico problema da dominação das minorias dentro de um sistema político, que não é aplicada apenas pela opinião, mas por interesses ou nacionalidades.

O princípio da autodeterminação, baseado em uma ética global do direito à diferença, tem sido afetado por um novo interesse em identidade cultural e diferença cultural, que reflete, dessa forma, nas normas e nos sistemas institucionais surgidos a partir da afirmação das identidades específicas e, portanto, da interculturalidade. Nesse sentido, no âmbito das relações internacionais é que surge a primeira arena em que hoje se discutem políticas multiculturais, como um direito humano universal.

No entanto, o conceito de autodeterminação traz a ideia de que nacionalidades podem certamente determinar, elas próprias, seus limites territoriais e, portanto, seu status político. A justificação ética funda-se no princípio ou ideia de que agentes individuais possuem direito à sua própria existência. Entre as condições de existência, encontra-se claramente a habilidade para se comprometer em relação aos seus próprios padrões culturais e morais (GOLD, 2000, p. 6). Dessa forma, “[...] self-determination is based on the idea that encompassing groups are vitally important for the well being of the their members." (DHABOUR, 1998, p. 5). A fonte mais ampla da autodeterminação fundamenta-se, portanto, no direito à autonomia (GHAI, 2003).

\footnotetext{
Multiculturalismo, justiça multicultural, direitos coletivos, cidadanias plurais são hoje alguns dos termos que procuram jogar com as tensões entre a diferença e a igualdade, entre a exigência de reconhecimento da diferença e de redistribuição que permita a realização da igualdade. Estas tensões estão no centro de lutas de movimentos emancipatórios que, contra as reduções eurocêntricas dos termos fundamentais (cultura, justiça, direitos, cidadania), procuram propor noções mais inclusivas e, simultaneamente, respeitadoras da diferença de concepções alternativas da dignidade humana. (SANTOS, 2003, p. 25).
}

Baseado na ideia do direito à própria existência, o princípio da autodeterminação faz com que grupos de indivíduos sejam distinguidos por um número de feições particulares, ou caracteres comuns, como a cultura particular de socialização, a identificação dos seus membros pensada como um processo de reconhecimento mútuo e, principalmente, mediante uma predominante forma de identidade pessoal. Nesse contexto, para Arendt (1974), a autodeterminação constitui a capacidade de um coletivo social emancipar-se de poderes hegemônicos, percebidos como opressivos, discriminatórios e injustos, impedindo, dessa forma, o livre exercício da vida 
em comum, ferindo, portanto, o direito básico à dignidade humana. Uribe (2003, p. 223) complementa essa ideia de Arendt, na qual se autodeterminar implica assumir livremente e sem interferências o próprio devir como povo e como conjunto social, decidindo sobre as regras da convivência e sobre o tipo de ordem política considerada mais adequada de acordo com os padrões culturais.

A autodeterminação, como foi pensada pelas ciências sociais tradicionais, parecia conduzir inevitavelmente à independência política, à fundação de um Estado soberano, próprio e distinto que representasse o coletivo tanto no contexto interno quanto externo. Não obstante, a emergência no cenário público de atores sociais com reivindicações específicas associadas ao reconhecimento das diferenças de gênero, idade, etnia, cultura, desenvolvimento desigual ou condição social, entre outras, levou a uma redefinição dos conteúdos da autodeterminação política em termos de alta complexidade. Estas lutas pelo reconhecimento já não têm como destino teleológico a fundação de um Estado moderno, estão antes permitindo o advento de uma nova matriz política que já não seria centrada no Estado, mas descentralizada com múltiplos pontos que outorgam sentidos e direções diferenciadas às tensões e aos conflitos da vida social. (URIBE, 2003, p. 223).

Partindo dessa premissa, parafraseando Uribe (2003), a autodeterminação pode ser desenvolvida em múltiplas esferas da vida social, sendo posta em ação por diversos sujeitos que, de acordo com suas particularidades culturais, econômicas e políticas, desenvolvem ações e discursos contra-hegemônicos, sem que isso venha a significar a independência política ou a criação de um novo Estado soberano.

Tal conceito determinou uma mudança (necessária) sob a visão dos direitos humanos. A partir da (re)conceitualização dos direitos do homem enquanto direito a se autodeterminar, os direitos humanos passaram a incorporar novos conceitos, visto que se autodeterminar exige a superação de uma cultura homogênea e, portanto, a negação de qualquer modelo cultural que vise excluir ou assimilar outras culturas e assim negar a diversidade (TULLY, 1995). ${ }^{1}$

Nos Estados em que existem minorias étnicas, religiosas ou lingüísticas, não será negado o direito que assiste às pessoas que pertençam a essas minorias, em conjunto com os restantes membros do seu grupo, ter sua própria vida cultural, professar a sua própria religião e utilizar sua própria língua. (GHAI, 2003, p. 51).

Pode-se perceber que o direito à autodeterminação ${ }^{2}$ levou a categoria dos direitos humanos a incorporar valores como o direito ao desenvolvimento, ${ }^{3}$ pluralis-

\footnotetext{
1 O autor defende que uma ordem multicultural não poderá negar o direito à autoderminação e, portanto, não poderá ser justa caso haja oposição às aspirações distintas de autogoverno. É, portanto, indispensável o estabelecimento de um Estado multiétnico para a efetivação dos direitos humanos (re)definidos a partir do direito à autodeterminação.

2 É interessante ver a análise de Ghai (2003) sob o direito à autodeterminação e seus desdobramentos éticos, filosóficos, políticos e jurídicos, principalmete a partir de alguns documentos internacionais sob tal direito.

3 A Declaração das Nações Unidas sobre o direito ao desenvolvimento afirma que: “[...] o direito ao desenvolvimento é um direito humano inalienável, em virtude do qual qualquer pessoa e todos os povos têm o direito de participar do desenvolvimento econômico, social, cultural e político, de para ele contribuir e dele desfrutar, e em que todos os
} 
mo dos direitos humanos, direitos dos povos indígenas e, como consequência destes, a reconceituação dos direitos a partir do conceito de multiculturalismo e da interculturalidade. ${ }^{4}$

Isso leva a outro fundamento, o de que o princípio da autodeterminação exige para a sua funcionalidade a condição necessária de que o Estado-nação proporcione condições para a sua realização. Isso demonstra que a conexão entre culturas particulares (direito à própria existência) e a capacidade do Estado em proporcionar um contexto cultural adequado se funda em um único direito, "o direito à cultura", ou seja, o direito a participar livremente de uma forma cultural diversa.

Em todos os casos, tudo isso levaria ao problema da redistribuição social, política e econômica, o que não poderia simplesmente ser focalizado como problema único dos sistemas democráticos, na medida em que o direito à autodeterminação envolve necessariamente o uso de recursos naturais e humanos para a produção de metas de satisfação das necessidades básicas em âmbito local. Portanto, isso inclui o direito à aplicação de recursos institucionais por parte do Estado, para o desenvolvimento dos diversos sistemas culturais dentro de um mesmo território e de satisfação de suas necessidades materiais (incluindo as formas necessárias para o desenvolvimento de suas formas culturais de vida e costumes). Dessa forma, "[...] a resistência e as alternativas terão possibilidades de sucesso apenas na medida em que sejam capazes de alcançar esse reconhecimento e essa legitimidade por parte do Estado." (SANTOS, 2001, p. 138). Em outras palavras:

If a group of persons living within a well-defined region of a country and pursuing a distinctive way of life is systematically disadvantaged by an entrenched and continuing pattern of discrimination in the allocation of goods and resources that prejudicially affects their ability to pursue their own way of life, that group has a right to redress through assertion of a principle of self-determination into allocation and management of its own goods and resources. (DHABOUR, 1998, p. 10).

A análise disso tudo nos leva a concluir que o princípio à autodeterminação, tido como direito dos povos de culturas, territórios e sistemas políticos diferentes de produzirem as metas à satisfação de suas necessidades culturais, sociais e econômicas, demonstrou os problemas das injustiças e opressões políticas, econômicas e,

\footnotetext{
direitos humanos e liberdades fundamentais possam ser plenamente realizados." (Art. 1.1) Afirma ainda que a pessoa humana "[...] é o sujeito central do desenvolvimento e deveria ser participante ativo e beneficiário do direito ao desenvolvimento (Art. 2.2)." Logo, "Os Estados têm o dever e o direito de formular políticas nacionais adequadas ao desenvolvimento, que visem o aumento constante do bem-estar de toda a população e de todos os indivíduos, com base na participação ativa, livre e significativa no desenvolvimento e na distribuição justa dos recursos.” (Art. 2.3). Disso, afirma Ghai (2003, p. 575) que "[...] uma definição mais ampla de desenvolvimento o vê como um processo econômico, cultural, social e político abrangente que vise o aumento constante do bem-estar de toda a população e de todos os indivíduos."

4 Para Ghai (2003), o multiculturalismo veio reforçar a luta contra-hegemônica dos direitos humanos frente à homogeneização neoliberal, levada a cabo pela ideologia política da governação global no âmbito dos direitos humanos. Para a autora, o multiculturalismo pertence ao período contemporâneo da globalização e é visto como um instrumento de luta para combater os legados do racismo e assegurar um sistema social e político mais justo.
} 
principalmente, a opressão cultural que muitos povos enfrentam, o que demonstra que a principal opressão se determina pelo grave problema da redistribuição dos recursos institucionais. Tal categoria de direito traz as discussões também sobre a questão dos povos indígenas e a denegação de direitos culturais, sustentados pela autodeterminação.

\section{A interculturalidade e os direitos dos povos indígenas: entre o colonialismo liberal e o pensamento pós-colonialista}

Santos (2011, p. 208) institui dois grandes processos ou fundamentos da modernidade: a desigualdade e a exclusão como forma de pertenças hierarquizadas. Em relação ao sistema da desigualdade, a pertença acontece pela integração subordinada; já na exclusão, a pertença paradoxalmente ocorre pela própria exclusão. Em relação ao primeiro, implica um sistema hierárquico de integração social, já o segundo assenta-se na dominação pela segregação (pertence-se pela forma como é excluído). Tanto Marx quanto Foucault foram para o sociólogo português os teóricos que mais descreveram esses dois processos. Marx estabeleceu muito bem a relação capital/trabalho na sociedade capitalista, assentado na desigualdade entre ambos, baseado na exploração. Se Marx foi o grande teorizador da desigualdade, firmada esta em critérios econômicos, já Foucault é para Santos o grande teorizador da exclusão. A grande diferença é que se a desiguldade é baseada em critérios econômicos de desigualdade, a exclusão é um fenômeno cultural e social, ou como afirma esse autor, um fenômeno civilizacional. Trata-se de um processo histórico no qual uma determinada cultura cria um dispositivo de normalização que é tanto qualificador quanto desqualificador.

A exclusão da modernidade é traduzida em regras jurídicas que vincam, elas próprias, a exclusão. Na base da exclusão está uma pertença que se afirma pela não pertença, um modo específico de dominar a dissidência. Assenta num discurso de fronteiras e limites que justificam grandes fracturas, grandes rejeições e segregações. Sendo culturais e civilizacionais, têm consequências sociais e econômicas. (SANTOS, 2011, p. 282).

Esses dois sistemas, de exclusão e desigualdade, característicos da modernidade, para o sociólogo português, encontram-se firmados em duas formas de hierarquização, que são híbridos, pois comportam ambas as formas: o racismo e o sexismo. Mesmo sendo formas de exclusão, tanto o racismo quanto o sexismo estabelecem uma forma de hierarquização pelo trabalho. ${ }^{6}$ A desigualdade entre o capital e o tra-

\footnotetext{
5 A modernidade inicia com o discurso da emancipação, calcada nos princípios basilares da igualdade. No entanto, com a sua convergência com o capitalismo, a partir do século XIX, inicia-se tanto o processo de desigualdade quanto o de exclusão. Dois grandes autores, para Santos, representam bem esses elementos (desigualdade e exclusão): Marx e Foucault.

6 Em relação ao racismo, o principio da exclusão assenta-se na hierarquia das raças, visto que a integração desigual ocorre primeiro pela exploração colonial (trabalho forçado e escravatura) e depois pela imigração. Em relação
} 
balho, a exclusão, o racismo e o sexismo foram construídos socialmente como forma de hierarquização da modernidade, sendo, para Santos (2011, p. 282), acolhidos pelas Ciências Sociais por meio do conceito de Globalização. ${ }^{7}$

No sistema mundial, cruzam-se assim, os dois eixos: o eixo socioeconômico da desigualdade e o eixo cultural-civilizacional da exclusão/segregação. Se o imperialismo - e a sua manifestação mais recente, a globalização neoliberal - é a expressão mais evidente do eixo socioeconômico, o orientalismo - e sua mais recente encarnação, a guerra das civilizações - é a expressão mais evidente do eixo cultural, civilizacional.

O ponto crucial está na premissa sustentada pelo autor de que o dispositivo ideológico de gestão moderna/capitalista da desigualdade e da exclusão utilizado no qual fundamentaram tanto o racismo quanto o sexismo é o universalismo. ${ }^{8}$ Este, assume duas formas: o universalismo antidiferencialista que opera a negação das diferenças e o universalismo diferencialista que opera a absolutização das diferenças. A negação das diferenças é operada pela homogeneização (impedindo comparações culturais densas e complexas), já a absolutização das diferenças opera pelo relativismo que torna incomparáveis as diferenças pela ausência de critérios transculturais (SANTOS, 2011, p. 283). Ambos os critérios de universalismo criados pela modernidade permitiram a aplicação de critérios abstratos de normalização, que, para o autor, foram baseados em uma espécie de diferença "que tem poder" social para negar as demais ou para declará-las inassimiláveis ou incomparáveis. Portanto, e aqui está, talvez a principal premissa defendida pelo autor, a qual pode ser resumida da seguinte forma: a teoria política liberal calcada na teoria jusnaturalista-racionalista-contratualista - máximo da teoria teórica da modernidade liberal-capitalista - sempre privilegiou o universalismo antidiferencialista que acionou politicamente por meio das ideias de cidadania e direitos humanos. Seguindo esse raciocínio, para o autor, o direito natural racionalista dos séculos XVII e XVIII também faz parte desse processo, na medida em que serviu para legitimar quer o "despotismo iluminado" quer as ideias liberais e democráticas que conduziram a Revolução Francesa, partindo, portanto, do modelo de racionalidade descrita. É possível perceber claramente no pensamento do autor a premissa da contrariedade dos direitos naturais universais como forma emancipatória. Além do mais, e seguindo esse raciocínio, baseado na função do Estado capitalista, como gestor das desigualdades, afirma Santos (2011) que o aprimoramento dos direitos humanos mediante o Welfare-State serviu como

ao sexismo ocorre pela distinção entre espaço público e privado e pela integração desigual da mulher na força do trabalho e no seio da família. Enquanto o sistema da desigualdade se assenta paradoxalmente na igualdade, sendo portanto, o contrato de trabalho um contrato entre livres e iguais, a exclusão assenta na diferença.

7 Isso fica claro para o autor à medida que tais sistemas foram alocados no espaço/tempo mundial, por meio da globalização hegemônica, levando a formas de trabalho escravo e exclusão por genocídios de povos e comunidades indígenas.

8 Note-se que o universalismo é o grande fundamento de toda a teoria moderna dos direitos humanos. 


\section{forma de gestão capitalista, é dizer, ao Estado providência coube a gestão das desi- gualdades e à teoria dos direitos humanos coube a gestão da exclusão. ${ }^{9}$}

À luz do que fica dito, parece evidente o fracasso do modelo ocidental de modernidade capitalista na gestão controlada da desigualdade através da integração assente nas políticas redistributivas do Estado providência. Do mesmo modo, parece ter fracassado a gestão controlada dos processos de exclusão. No Estado moderno, dominou a ideologia do universalismo antidiferencialista e, em alguns Estados, como, por exemplo na França, ele foi elevado ao extremo. ${ }^{10} \mathrm{~A}$ cidadania política tem sido concebida como justificando a negação dos particularismos, das especificidades culturais, das necessidades e das aspirações vinculadas a microclimas culturais, regionais, étnicos, religiosos ou raciais. A gestão da exclusão deu-se, pois, por via de assimilação prosseguida por uma ampla política cultural orientada para a homogeneização. Os camponeses, os povos indígenas e os imigrantes estrangeiros foram os grupos sociais mais diretamente atingidos pela homogeneização cultural descaracterizadora das suas diferenças. Para além deles, outros grupos sociais discriminados por via de processos de exclusão, como mulheres, homossexuais, toxicodependentes foram objetos de várias políticas todas elas vinculadas ao universalismo antidiferencialista, neste caso sob a forma de normas abstratas sempre traduzidas em lei. (SANTOS, 2011, p. 292). ${ }^{11}$

\section{Partindo de tais constatações teóricas, a teoria emancipatória dos direitos humanos, baseada na hermenêutica diatópica e na interculturalidade abrangendo esta o constitucionalismo multicultural e a cidadania pós-nacional e cultural, é parte de um processo mais amplo, de transição da modernidade para a pós-modernidade e pós-colonialidade de oposição. Sobre isso, cabem outras considerações. De acordo com o sociólogo português, para uma teoria pós-moderna dos direitos humanos é}

\footnotetext{
9 O universalismo antidiferencialista, teve uma função bem específica dentro da teoria política liberal. Para Santos (2011), ele confrontou a desigualdade social por meio de políticas sociais do Estado providência, nos países centrais mediante as políticas desenvolvimentalistas, e nos Estados periféricos e semiperiféricos mediante políticas assimilacionistas. Esse argumento baseia-se, justamente, na função do Estado capitalista, que, para o sociológo português, tem como função geral manter a coesão social em uma sociedade atravessada pelos sistemas de desigualdade e de exclusão (SANTOS, 2011). Essa função política do Estado capitalista, especificamente no que diz respeito à desigualdade, consiste em manter a desigualdade dentro dos limites que não inviabilizem a integração subordinada, designada de ilusão social pelas políticas assistencialistas estatais. Aqui está a crítica feita ao modelo do Welfare State: os direitos sociais e econômicos universais baseados em políticas compensatórias como fome-zero, bolsa-família, bolsa-escola, entre outras formas, são os mecanismos modernos para manter os níveis de desigualdade em níveis tolerados. No que diz respeito ao viés da exclusão, a função do Estado capitalista consiste em distinguir, entre as diferentes formas de exclusão, aquelas que devem ser objeto de assimilação, ou pelo contrário, objeto de segregação e expulsão ou ainda extermínio. Esta distinção é feita a partir de critérios pelo qual o Estado estabelece as diversas formas de dicotomização: perigoso e não perigoso, criminoso e não criminoso, povos indígenas e povos civilizados, etc.

10 Esse debate na França, assenta claramente na questão dos valores liberais versus religião islâmica.

11 De acordo com o autor, essa gestão controlada da exclusão baseada em políticas assimilacionistas (como por exemplo, reintegração social, reeducação, extensão da cidadania e no caso das mulheres com acesso ao mercado de trabalho) em nenhum momento se buscou eliminar a exclusão, mas apenas uma gestão tolerável. No entanto, considerando-se o espaço tempo global, baseado no modelo neoliberal, há a ocorrência de um fator mais profundo, qual seja, a metamorfose do sistema da desigualdade em sistema de exclusão. Tal metamorfose, assenta-se na transformação pela qual o trabalho está a passar. À medida que se rarefaz o trabalho, a integração garantida por ele se tornar mais precária. E, nesse sentido, o trabalho passa a definir mais as situações de exclusão do que as situações de desigualdade. Grupos sociais, incapazes de reentrar no mercado de emprego, em razão das mudanças bruscas que estão a ocorrer, saem já de um cruel sistema de desigualdade para entrar em um sistema mais cruel ainda de exclusão. Agravando tal situação, perante o sistema de exclusão, o Estado providência encontra-se desarmado, visto que sua situação pressupõe uma relação salarial estável, mesmo quando se trata de produzir assistencialismo para os desprovidos.
} 
necessária, como consequência, a construção de uma teoria pós-moderna. A ideia de pós-modernidade para Santos (2011) visa radicalizar a crítica à modernidade ocidental buscando não converter a noção de transformação emancipatória em uma nova forma de opressão social. Por isso, designa, ao contrário da visão hegemônica de pós-modernismo e pós-modernidade, a ideia de pós-modernismo de oposição baseando tal teoria nas experiências das vítimas e dos grupos sociais que tinham sofrido com o exclusivismo epistemológico da ciência moderna. Logo, a base da teoria está em aprender com o sul. ${ }^{12} \mathrm{O}$ termo pós-moderno de oposição, surge, portanto, pela crítica do autor às visões hegemônicas de pós-modernidade. Isso porque a ideia de "pós-modernidade" aponta para a descrição que a modernidade fez de si mesma (SANTOS, 2011, p. 27) e dessa medida pode ocultar a violência material imposta pelo colonialismo. Essa violência nunca foi incluída na autorrepresentação da modernidade, visto ser o colonialismo concebido como uma missão civilizadora dentro do marco histórico do Ocidente. ${ }^{13}$

Partindo de tais constatações feitas pelo sociólogo português sobre a gestão da exclusão e da desigualdade, a partir de uma teoria universal dos direitos humanos, podemos centrar a discussão sobre os direitos interculturais dos povos indígenas. Uma das características desses povos, em especial na América, é, para Santos (2003, p. 151), a violação de seus direitos por meio da história moderna e da resistência em caso de situações desiguais. No atual contexto, pressionados pelo Consenso de Washington, os Estados periféricos têm entrado em "novos" projetos de ajustes estruturais e desenvolvimento econômico, financiados tais projetos, basicamente, pelas ETNs e instituições financeiras internacionais que, para a efetivação de tais metas econômicas, levam-nas a cabo em terras de grupos indígenas, destruindo seu estilo de cultura. A discussão sobre o direito indígena se torna de suma importância, visto que $300 \mathrm{mi}$ lhões de pessoas pertencentes a povos indígenas vivem em todas as partes do mundo (SANTOS, 2001, p. 153). Percebe-se, com isso, que a questão dos povos indígenas é um caso especial dentro de uma categoria mais ampla: a minoria étnica (SANTOS, 2001).

Sem se aprofundar sobre a discussão acerca da minoria étnica e do direito indígena (SANTOS, 2001, p. 161), denota-se que ambos são, para a teoria política liberal, resíduos pré-modernos que passaram a interferir de forma negativa, primeiramente, no mecanismo de regulação econômica e, em segundo, na obrigação política existente entre cidadãos individuais e o Estado. Além do mais, para a teoria liberal os direitos são prerrogativas de indivíduos e somente destes. Com isso, sustenta-se que os direitos coletivos são supérfluos, à medida que os direitos humanos (incluindo os direitos individuais) são universais, determinando a igualdade formal de tais direitos. No entanto, como ressalta Santos (2001, p. 157), o ato de que a grupos específicos seja outorgada uma proteção jurídica específica não choca com o princípio

\footnotetext{
12 Como veremos mais adiante, tal ideia constitui-se na base para a política de direitos humanos.

13 Nesse sentido, para Santos, a grande questão é saber se "pós" em pós-moderno significa o mesmo que "pós" em pós-colonial. Trata-se, portanto, em saber os limites de uma crítica radical da modernidade.
} 
liberal, já que os direitos pertencem, nesses casos, aos indivíduos e não a entidades coletivas às quais eles pertencem.

El paradigma liberal se encuentra em el origen de la aversión de los estados al reconocimiento de derechos coletivos de grupos diferentes a ellos mismos. Los derechos colectivos son vistos como amenazas al principio de la soberania $y$ combustible de las tensiones domésticas [...] Em primer lugar, a pesar del reconocimiento internacional de los derechos humanos universales como proceso civilizador, la discriminación contra los pueblos indígenas y las minorias étnicas ha sido praticada e incluso respaldada juridicamente a lo largo de los anõs [...] En segundo lugar, trás una larga historia de genocidio y etnocidio, de politicas de exclusión o integración impuestas, la eliminación no puede ser lograda a través de la mera igualdade formal frente a la ley. (SANTOS, 2001, p. 159).

A luta pelos direitos coletivos dos povos indígenas deve partir primeiramente de uma política de reconhecimento e de pluralidade jurídica, entendendo como tal a obrigação dos Estados nacionais de reconhecerem os direitos coletivos, de um lado, e, de outro, possibilitarem a criação de uma competência jurídica interna, viabilizando o desafio ao monopólio da produção e distribuição do direito. ${ }^{14} \mathrm{O}$ direito à autodeterminação como um "direito à cidadania" abrange, como visto, não somente seu aspecto político, mas, também, seu viés econômico, cultural e social. Todos os povos têm direito de decidir sobre sua própria vida comunitária, suas leis, suas regras, suas instituições, símbolos e seu próprio destino político. A exigência da autodeterminação, em outras palavras, está centrada no direito à terra, aos recursos históricos, bem como à organização cultural autônoma (abrangendo a identidade cultural). Para Santos (2001, p. 163), o direito à autodeterminação firma-se em três pressupostos: novo direito, ${ }^{15}$ novo Estado e nova comunidade. ${ }^{16}$ Em outras palavras, essa proposta assinala a necessidade de uma inovação política que vá além do paradigma proposto pelo modelo liberal, devendo, com isso, ser a autodeterminação reconhecida como condição jurídica prévia e política alternativa às medidas integracionistas e genocidas (SANTOS, 2001, p. 169).

O paradigma liberal, como muito bem demonstrou Dantas (2012), é caracterizado externamente pela construção de espaços transnacionais com evidente predomínio do interesse econômico e, no âmbito interno dos Estados, pela diversidade sociocultural e étnica historicamente invisibilizada pelo violento processo de homogeneização social e cultural.

Indigenous people occupied defined territory before national States were created and were frequently excluded from accessing the rights that were given to the members of the predominant society.To ensure the segregation of indigenous people they were often expelled from their original territories. Normally, indigenous people do not compete with national state in terms of wanting to form a different

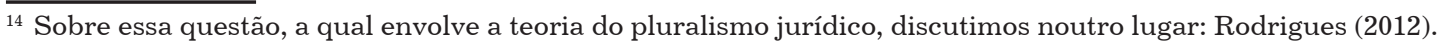

${ }^{15}$ Aqui se centra o direito à dupla legalidade: criar leis próprias e a luta por um direito coletivo.

${ }^{16}$ Esse último abrange o anterior. Refere-se tanto ao autogoverno e ao controle de seus recursos quanto, também, à crítica ao Estado para o estabelecimento de uma nova forma de soberania (dispersa).
} 
state. Their principal claims lies in the recognition of their political autonomy and equal access to basic rights and freedom. (PALAFOX, 2011, p. 59-77).

Pugnar por uma nova cidadania significa romper limites. Os clássicos limites conceituais à própria cidadania, ao Estado e ao direito. Assim é preciso refletir como a moldura do Estado monocultural, bem como a do direito monístico provocaram a exclusão, entre outras, das diferenças étnicas e culturais, de modo velado pela suposta universalidade do princípio da igualdade e pelo difundido conceito de cidadania legal, igualitária e indiferenciada, baseada na dialética interno/externo e, em termos identitários, nós e os outros. Desse modo, no intento de romper com a exclusão institucionalizada que marcou a história dos povos indígenas brasileiros, propõe-se para estes uma cidadania nova e (re)significada - com novos e diferenciados processos e instrumentos para o seu exercício - baseada no alargamento da ideia de vínculos sociais, culturais, jurídicos e políticos de pertença concomitante às suas sociedades e culturas particulares e ao Estado (DANTAS, 2012, p. 4).

Nesta perspectiva o primeiro dos elementos essenciais para a entrada dessa proposta em cena é a ideia/modelo de Estado Nacional que pressupõe nação e cultura únicas como elementos da base humana e social. É preciso que o Estado se reconheça como plurinacional e multicultural para que os direitos diferenciados próprios à cidadania indígena sejam efetivos, tanto no âmbito individual e coletivo das pessoas, como de organização institucional complexa dos âmbitos públicos estatais como, por exemplo, ocorre na Bolívia e no Equador; em segundo, a própria ideia fundante do sistema democrático representativo moderno - a representação - definida pelo voto. Este âmbito envolve uma racionalidade baseada em opostos, as oposições binárias criticadas por Boaventura de Sousa Santos na configuração da sua teoria sobre o pensamento abissal ${ }^{17}$ caracterizador das clássicas relações jurídicas, políticas e sociais e sociais modernas, personificadas nos opostos representante e representado, que para a maioria dos povos indígenas não faz sentido, como é o caso do povo Xavante; por último, o voto como um direito decorrente da cidadania indígena, deve atender às configurações étnicas e culturais das subjetividades e territorialidades específicas e diferenciadas pelos usos, costumes e tradições reconhecida no Art. 231 da Constituição Federal brasileira de 1988. Esse conjunto de elementos críticos ao sistema eleitoral formal e tradicional encontra, do alistamento do eleitor e do registro de candidaturas, aos processos de votação e exercício de mandatos, enorme barreira decorrente de fatores culturais, linguísticos, territoriais e administrativos (DANTAS, 2012, p. 7).

Por outro lado, a consequência dessa real incompatibilidade do sistema estatal moderno centrado, prioritariamente, no exercício da democracia mediante representação, com as formas diretas e comunitárias dos povos indígenas, de modo geral, vivenciarem o Governo e o poder, é a geração de um ambiente de pouca ${ }^{18}$ par-

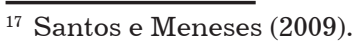

${ }^{18}$ Observa-se que, apesar da importância nos contextos políticos atuais de refundação do Estado, no caso brasileiro, o Governo indígena de municípios, muitos com intensa população desses povos, restringe-se a seis prefeitos eleitos no pleito de 2008. O Estado do Amazonas conta com dois municípios governados por índios, São Gabriel da Cachoeira e Barreirinha; Roraima, igualmente, com dois, Uiramutã e Normandia, Paraíba, com um, em Marcação e, por último, Minas Gerais, também com um em São João das Missões (DANTAS, 2012).
} 
ticipação indígena tanto na qualidade de eleitores votantes quanto de candidatos votados. Ressalte-se que apesar de estratégica, essa ainda é uma questão tangenciada no sistema eleitoral brasileiro no que se refere ao reconhecimento constitucional ${ }^{19}$ dos direitos diferenciados dos povos indígenas (DANTAS, 2012, p. 6).

De acordo com Fariñas Dulce (2000 apud DANTAS, 2012), a partir do novo conceito da pluralidade cultural e normativa, baseada no pluralismo jurídico e, portanto, das exigências de reconhecimento jurídico e político das diferenças e das heterogêneas identidades étnico-culturais, bem como na insuficiência conceitual da noção clássica de cidadania, afirma a autora a necessidade de repensar a categoria moderna da cidadania a partir de dois espaços reguladores e interdependentes. $\mathrm{O}$ espaço particular, interno aos Estados nacionais que deve gerar a noção de cidadania fragmentada ou diferenciada e o espaço externo, transnacional, global, não vinculado à regulação do Estado nacional e à sua territorialidade, gerador da noção de cidadania cosmopolita ou global (FARIÑAS DULCE, 2000, p. 35-36). A cidadania diferenciada, segundo a autora, deve ser fundada no reconhecimento do direito à diferença como valor jurídico e político que propicie - calcada em princípios democráticos - a preservação e a manifestação da identidade, bem como a participação pública nos âmbitos político, social, cultural e econômico, desde e com suas diferenças. ${ }^{20}$ Isso equivale dizer que é a participação

\footnotetext{
${ }^{19}$ A Constituição boliviana de 2009, que tomamos como paradigma, reconhece o Estado como plurinacional, comunitário, intercultural (Art. $1^{\circ}$ ). Reconhece os sistemas de governo democráticos participativo, representativo e comunitário (Art. 11) e, entre os direitos políticos, os direitos de participação dos povos indígenas originários campesinos de praticarem seus processos eleitorais segundo suas normas e procedimentos específicos relacionados às suas culturas (Art. 26), garantindo a participação indígena na composição do Tribunal Supremo Eleitoral (Art. 206, II).

${ }^{20}$ Todavia, a tarefa não é simples. Basta, no caso dos povos indígenas, o dado depopulacional comparativo entre o que foram, em números, os povos indígenas no início do processo de colonização e a população indígena atual. De aproximadamente 10 milhões, foram reduzidos a menos de um milhão (segundo dados do IBGE, divulgados pelo Instituto Socioambiental no site: <http://pib.socioambiental.org/pt/c/0/1/2/populacao-indigena-no-brasil>) para constatar que as relações históricas dos povos indígenas com a sociedade nacional resultaram em situações violentas de extermínio físico, o que se pode caracterizar, hoje, como processos genocidas, que, por conseguinte, geraram extermínios culturais configuradores de etnocídios e epistemicídios, na expressão de Santos. Para o autor, "O privilégio epistemológico que a ciência moderna se concede a si própria é, pois, o resultado da destruição de todos os conhecimentos alternativos que poderiam vir a pôr em causa esse privilégio. Por outras palavras, o privilégio epistemológico da ciência moderna é produto de um epistemicídio. A destruição de conhecimento não é um artefato epistemológico sem consequências, antes implica a destruição de práticas sociais e a desqualificação de agentes sociais que operam de acordo com o conhecimento em causa." (SANTOS, 2011, p. 242). Do mesmo modo, foram vítimas as populações negras, os escravos libertos que não tinham qualquer condição material de sobrevivência, pois não tinham trabalho, nem terra, enfim, os elementos necessários para a satisfação das necessidades materiais e espirituais. Por outro lado, pode-se dizer, também, que a política assimilacionista levada a cabo pelo Estado, por meio dos programas institucionais de integração dos povos indígenas à comunhão nacional, visando à emancipação individual e à integração no sistema produtivo capitalista e consequente descaracterização ou até o desaparecimento das respectivas sociedades, em nome da civilização, da liberdade e da igualdade, consistiu violências institucionalizadas que marcaram negativamente a concepção do ser indígena estereotipado pelas visões tópicas atuais, no propósito de classificar as pessoas indígenas e seus respectivos direitos por meio de conceitos ou categorias ultrapassadas, tanto no campo da ciência quanto no do direito. Por meio de projetos institucionais no âmbito do "Programa de Desenvolvimento de Comunidades Indígenas", administrativamente conhecidos como "Programas de Desenvolvimento Comunitário". Na prática, esses programas desenvolveram uma desastrosa sistemática de substituição dos sistemas de produção de subsistência baseados na policultura tradicional dos povos indígenas, pelo sistema de agricultura capitalista intensiva e monocultora, principalmente no Sul do país. Segundo o discurso oficial, "Estes programas de desenvolvimento comunitário são elaborados de acordo com as aspirações das comunidades indígenas, e têm como objetivo a estruturação dos setores da economia de subsistência e de comercialização, desenhando ações concretas para o engajamento das comunidades indígenas com grau de aculturação mais elevado, no processo de desenvol-
} 
do sujeito diferenciado, duplamente contextualizado e relacionado no seu universo particular e comunitário bem como no âmbito do Estado. Já a cidadania cosmopolita ou global seria aquela que transcende ${ }^{21}$ as fronteiras e a soberania do Estado-nação, transnacionaliza-se, uma categoria de cidadania globalizada (FARIÑAS DULCE, 2000, p. 36-44 apud DANTAS, 2012).

[...] historicamente, foi negado às diferenças o direito de expressar suas identidades e especificidades socioculturais tendo em vista a violência dos processos de morte lenta, física e cultural, ou seja, da "ideia de inevitabilidade de seu desaparecimento como experiência coletiva viva, capaz de repor suas instituições a cada ato, capaz de manter, no tempo, uma cultura própria". Em segundo, na atualidade, a inefetividade das normas constitucionais de reconhecimento impedem seu exercício pleno, portanto, é tímida a participação política dos índios e dentre outras diferenças nos âmbitos do Estado se constitui em um vir a ser realidade o que impulsiona os movimentos sociais a reivindicar direitos de participação e construir espaços de luta que extrapolam o contexto do Estado nacional [...] A possibilidade de se antepor à inevitabilidade das leis do desenvolvimento capitalista nos remete à questão fundamental: como impedir a destruição dos povos indígenas? Como garantir a sua liberdade de existência? É no interior desse quadro que cumpre verificar se a extensão da cidadania às populações indígenas significará a sua sobrevivência e sua liberdade. Ou se, ao contrário, longe de implicar a condição de sua preservação, seria um golpe de morte na sua liberdade de viver e sobreviver e a implantação violenta de uma igualdade. Igualdade essa que, ao tudo "igualar", termina com as diferenças e, portanto, com a liberdade. (DANTAS, 2012, p. 13).

vimento econômico e social." (FUNDAÇÃO NACIONAL DO ÍNDIO, 1983, p. 3). Assim, em contextos históricos e políticos tão adversos tanto para os povos indígenas quanto para os grupos etnicamente diferenciados, a igualdade de direitos na perspectiva assimilacionista significa morte, porque representa um diluir-se no conjunto social homogêneo da sociedade nacional. Morte, quando não física, cultural. A cidadania clássica, portanto, como instituto fundado na igualdade e na liberdade, segue no significado, o mesmo destino (DANTAS, 2012, p. 14).

${ }^{21}$ No campo do direito internacional, percebe-se a instituição de mecanismos jurídicos transnacionais com o objetivo de efetivar tal direito dos povos indígenas, mesmo que um dos resultados dessa transnacionalização seja a dificuldade que encontram os povos indígenas para serem reconhecidos como "povos" e, portanto, legitimados para o exercício da autodeterminação. A Conferência Mundial sobre Direitos Humanos, realizada em Viena em 1993, considera que a negação do direito à autodeterminação constitui uma violação dos direitos humanos e enfatiza a importância da efetiva realização desse direito. Além disso, depois de declarar 1993 como o Ano Internacional dos Povos Indígenas, a ONU parece estar perto de adotar a Declaração Universal dos Direitos dos Povos Indígenas. O projeto da Declaração foi proposto pelo Grupo de Trabalho sobre Populações Indígenas da Subcomissão para a Prevenção da Discriminação e Proteção das Minorias da ONU. De qualquer forma, a convenção sobre povos indígenas, adotada em 1993 reconheceu “[...] aspirações destes povos a exercer controle sobre as suas próprias instituições, modos de vida e desenvolvimento econômico e a manter e desenvolver as suas identidades, línguas e religiões dentro do contexto dos Estados em que vivem." (GHAI, 2003, p. 571). Além do mais, os seus valores culturais e religiosos, as suas instituições e formas tradicionais de controle social devem ser preservadas. Da mesma forma, o sistema de propriedade da terra deve ser preservado (Arts. 14 e 17). Já a proposta da Declaração Universal vai mais longe, proclamando o direito indígena à autodeterminação, segundo o qual os povos indígenas devem "[...] estabelecer livremente seu status político e prosseguir livremente seu desenvolvimento econômico, cultural e social." (GHAI, 2003, p. 570). Tal princípio confere aos povos indígenas o direito à autonomia de governo ou ao autogoverno em relação aos seus assuntos internos e locais, reconhecendo seus direitos como direitos coletivos, inclusive o direito de preservar e consolidar suas características políticas, econômicas, culturais e sociais. (GHAI, 2003, p. 571). Mesmo sabendo que as normas internacionais são instrumentos criados pelos Estados e para estes, é preciso reconhecer que há uma progressiva preocupação pela situação e pela proteção dos povos indígenas no sistema das Nações Unidas. É um fato que, apesar da resistência de alguns governos que já se preparam para se opor à aprovação do projeto da Declaração, nos últimos anos os povos indígenas passaram a ser reconhecidos pela comunidade internacional como objeto e provavelmente como sujeitos do Direito Internacional. Essa crescente preocupação, evidentemente, foi marcada pelas pressões feitas pelos povos e organizações indígenas, inclusive nos Fóruns da ONU. É por isso que a Declaração inclui aspectos relevantes sobre os direitos culturais e étnicos coletivos: o direito à terra e aos recursos naturais, a manutenção das estruturas econômicas e os modos de vida tradicionais, o direito consuetudinário e o direito coletivo à autonomia. 
Em relação ao Estado brasileiro, por exemplo, considerando-se conceitos jurídicos nos quais a cidadania se vincularia ao conceito de Estado, poder-se-ia afirmar que em relação aos povos indígenas, na medida em que são sociedades sem Estado, possuindo ainda valores simbólicos e de organização social diferente da liberal, estes não seriam de sobremaneira cidadãos brasileiros. No entanto, visto que o Brasil estabeleceu como critério para a determinação da cidadania o jus solis, - cidadão é aquele que nasce no território nacional, os índios, individualmente, são legalmente cidadãos brasileiros. No entanto, “[...] são, paradoxalmente, cidadãos brasileiros e possuem identidades culturais conflitantes com a identidade homogênea nacional, portanto, a cidadania indígena é uma ficção." (SOUZA FILHO, 1983, p. 44-51 apud DANTAS, 2012). Nasce, com isso, uma ficção jurídica tensionada pela necessidade de conjugar, harmonizar os valores individuais da igualdade com os coletivos das diferenças (FARIÑAS DULCE, 2000, p. 399 apud DANTAS, 2012).

Deve-se lembrar que o discurso político e jurídico dominante baseado na ótica bem denunciada por Santos como um discurso universalista excluiu as sociedades indígenas ao longo da história a partir da ideologização e naturalização das diferenças culturais, considerando-as “[...] ora como bárbaras e selvagens, ora românticas e folclóricas, mas, sempre, e principalmente, como óbices à integração, unificação e desenvolvimento do Estado." (DANTAS, 2012, p. 15).

Tais grupos diferenciados - povos indígenas, negros, comunidades tradicionais - compõem a estrutura da sociedade brasileira, firmando-se como sociedades culturalmente diferenciadas da sociedade nacional, a qual poderíamos, utilizando as palavras de Santos, denominá-la sociedade nacional hegemônica. Apesar de ser a sociedade brasileira calcada na diversidade étnica e cultural, fundamento este da Carta Constitucional Democrática de 1988, as diferentes culturas tidas como colonizadas foram ocultadas ao longo da história por um longo processo de colonização e de construção do Estado nacional, processo que teve no direito positivado um dos mais fortes e poderosos mecanismos de exclusão da diferença cultural dos povos indígenas e das comunidades tradicionais, processo de exclusão que serviu de fundamento da política indigenista levada a cabo, primeiro pela Coroa portuguesa e, em seguida, pelo Estado brasileiro; ambos promoveram genocídios e etnocídios e se tornaram responsáveis pelo desaparecimento quase total de vários povos indígenas e de suas raízes culturais (DANTAS, 2012, p. 15).

A apreensão parcial que o direito positivado faz da realidade social, por meio de mecanismos de poder que valoram e privilegiam uma determinada forma de vida e práticas sociais como boas, com a consequente juridicidade amparada pelo Estado, institucionalizou, ao longo da história do direito no Brasil, a exclusão do espaço jurídico-político nacional, das pessoas indígenas e suas sociedades, suas vidas, seus valores e suas formas diferenciadas de construção social da realidade. Nesse sentido, os colonizadores portugueses desconsideraram a existência de povos autóctones, com organizações sociais e domínio territorial altamente diversificados e complexos, negando aos seus membros a qualidade de pessoas humanas ou de uma humanidade viável, motivo pelo qual justificavam a invasão e tomada violenta do território, a escra- 
vização, as guerras, os massacres e o ocultamento jurídico. O direito colonial e, posteriormente, o nacional seguiram o mesmo caminho. A formulação jurídica moderna do conceito de pessoa enquanto sujeito de direito, fundado nos princípios liberais da igualdade e liberdade que configuram o individualismo, modelo adotado pela juridicidade estatal brasileira e estampado no Código Civil de 1916, gerou o sujeito abstrato, descontextualizado, individual e formalmente igual, e classificou as pessoas indígenas, não como sujeitos diferenciados, mas, diminutivamente, entre as pessoas de relativa incapacidade, ou pessoas em transição da barbárie à civilização. Esta depreciação justificava a tutela especial exercida pelo Estado, os processos e ações públicas voltados para a integração dos índios à comunhão nacional, o que equivale dizer, transformar os índios em não índios. (DANTAS, 2012, p. 19).

De acordo com Dantas (2012), a cidadania diferenciada na sociedade multicultural deve expressar um repensar das noções clássicas de sociedade, de Estado e do direito e, consequentemente, do próprio conceito de cidadania, buscando, dialogicamente, a inserção pela participação democrática da pluralidade de sujeitos diferenciados desde seus contextos e identidades particulares, no contexto maior do Estado. Um ponto de partida, para o autor no que diz respeito à construção conceitual de uma nova cidadania diferenciada, que atenda à composição pluriétnica dos Estados contemporâneos, tanto intrínseca na realidade ibero-americana quanto provocada pela imigração nos países do primeiro mundo, é oferecido por Herrera Flores e Rodríguez Prieto (2000). Para esses autores, de acordo com Dantas (2012, p. 16), a cidadania não constitui um status, portanto, um sujeito não é cidadão, ele "tem" cidadania; assim, concebem-na como uma "técnica para o exercício da democracia" pelos pressupostos de que em primeiro lugar a cidadania diz respeito a algo mais além da pertença a um Estado-nação e à sua correspondente legalidade. No mundo contemporâneo existem múltiplos espaços e legalidades que fazem da cidadania algo mais complexo do que a simples nacionalidade. Em segundo lugar, a cidadania não outorga algum estado ontológico. Não se é cidadão. Se tem ou não se tem cidadania. Em terceiro lugar, que a cidadania não é um status, é uma técnica, um instrumento que usado corretamente pode nos permitir exercer a busca e a consolidação de outros instrumentos ou meios que nos aproximem do objetivo/projeto de autogoverno (DANTAS, 2012, p. 16).

Essa ideia de Estado pluriétnico e de cidadania multicultural foi um dos fundamentos do Estado brasileiro por meio da Constituição democrática de 1988, a qual reconheceu expressamente as diferenças étnico-culturais dos povos indígenas garantindo suas organizações sociais, usos, costumes, tradições, direito ao território e capacidade postulatória, fundamento, aliás, no direito expresso na Carta Magna à autodeterminação dos povos. No entanto, apesar de um grande avanço no marco da constitucionalização dos direitos dos povos indígenas, para que ocorra a sua efetivação prática, é de suma importância um processo dar vida às normas constitucionais pelo caminho jurídico-hermenêutico; já sob o prisma político se deve ampliar a participação democrática dos índios e de suas organizações, nas três esferas do Poder Público, 
possibilitando opinarem diretamente sobre qualquer assunto que lhes interesse. ${ }^{22}$ Sem isso, continuaremos a ter um avanço no âmbito na constitucionalização, mas de outro lado, continuaremos a agir de forma a negar-lhes os direitos básicos à participação e à construção de subjetividades distintas.

A terra é para os povos indígenas espaço de vida e liberdade. O espaço entendido enquanto lugar de realização da cultura. Para Tommasino, "cada sociedade elabora a sua concepção de tempo e de espaço conforme sua visão de mundo, a qual também orienta as suas práticas e relações sociais e simbólicas com a natureza e entre si." Isto significa que a construção dos modos de vida, da cultura, das pessoas e sociedades relaciona-se em um complexo de significados produzido social e coletivamente. A Constituição Federal brasileira define a categoria jurídica das terras indígenas, como aquelas tradicionalmente ocupadas pelos índios, habitadas em caráter permanente, utilizadas para suas atividades produtivas, imprescindíveis à preservação dos recursos ambientais necessários a seu bem-estar, necessárias à reprodução física e cutural, segundo seus usos costumes e tradições. Assim, a dignidade humana dos povos indígenas está condicionada ao respeito aos seus territórios, aos seus modos de vida e às suas instituições, como garantia prévia e imprescindível à satisfação das necessidades básicas. Portanto, o espaço e as formas de vida enquanto direitos consuetudinários, devem ser protegidos, sendo esse o comando constitucional. (DANTAS, 2012, p. 18).

O mais relevante, nessa crescente preocupação pelos direitos humanos dos povos indígenas, é a mudança de ênfase dos direitos "universais individuais" para os "direitos humanos coletivos." Mesmo com as devidas reservas por se tratarem de normas desenvolvidas pelos governos e para os governos - essa atenção aos direitos coletivos, a desejada aprovação da Declaração Universal sobre Direitos Indígenas e a sua ratificação pelos Estados subscritores configuram um novo espaço internacional no qual os povos indígenas poderão continuar a luta tanto para melhorar quanto para mudar a situação de discriminação e opressão a que têm estado submetidos nos últimos séculos no seio dos diferentes Estados Nacionais. No entanto, mesmo a questão dos direitos indígenas, vinculados à autodeterminação dos povos, quando inseridos em um conceito de democracia constitucional de matriz liberal-individualista, traz à tona a questão dos limites às categorias conceituais que firmaram e fundamentaram o constitucionalismo e a cidadania ocidental. ${ }^{23}$

\footnotetext{
${ }^{22}$ Nesse ponto, para os povos indígenas, a terra é o espaço de vida e de liberdade. Por isso, a importância da efetividade do direito à participação em qualquer discussão que envolva o espaço territorial indígena (SOUZA FILHO, 1998, p. 130). Veja, por exemplo, o que determina a Constituição da República Federativa do Brasil: "Art. 231 [...] § $1^{\circ}$ São terras tradicionalmente ocupadas pelos índios as por eles habitadas em caráter permanente, as utilizadas para suas atividades produtivas, as imprescindíveis à preservação dos recursos ambientais necessários a seu bem-estar e as necessárias à sua reprodução física e cultural, segundo seus usos, costumes e tradições.” (BRASIL, 1988). Pode-se dizer, a partir da exegese dos pressupostos constitucionais, que terras indígenas são aquelas habitadas pelos povos indígenas, enquanto espaço de vida, adequado às suas peculiaridades culturais e imprescindíveis para a sua reprodução física e cultural. Simbolizadas pela cultura, essas terras constituem verdadeiros territórios indígenas, porque orientados pelo evidente princípio que encerra a disposição constitucional, qual seja: a ocupação indígena é definida a partir dos usos, costumes e tradições de cada povo. Nesse sentido, afirma Souza Filho (1998, p. 134) que usos, costumes e tradições “[...] quer dizer direito, e, mais, direito consuetudinário indígena."

${ }^{23}$ Tais limitações têm sido enfrentadas por uma nova concepção de constitucionalismo, denominado constitucionalismo latino-americano, o qual se fundamenta justamente nas premissas da diversidade e da pluralidade. Nesse
} 


\section{Conclusão}

A cidadania foi tradicionalmente concebida como sinônimo de nacionalidade, ou como um vínculo jurídico entre Estados e indivíduos, formando a ideia de um corpo social com igualdade, homogeneidade, identidade e aspirações comuns. No entanto, a ideia de uma globalização contra-hegemônica defendida por Santos passou a demonstrar que no âmbito interno dos Estados as categorias conceituais operadas pela modernidade não poderiam ser aplicadas, visto a presença da diversidade sociocultural e étnica historicamente invisibilizada pelo violento processo de homogeneização, exclusão e desigualdade. Lutar, portanto, por uma nova cidadania significa romper os limites clássicos e conceituais à própria cidadania, ao Estado e ao direito. Um desses limites, e talvez o principal, é justamente a ideia institucional do Estado monocultural que, como muito bem demonstrou Dantas, com o direito monístico provocou a exclusão, entre outras, das diferenças étnicas e culturais, de modo velado pela suposta universalidade do princípio da igualdade e pelo difundido conceito de cidadania legal, igualitária e indiferenciada, baseada na dialética interno/externo e, em termos identitários, nós e os outros.

Desse modo, para se romper com a exclusão institucionalizada que marcou a história dos povos indígenas brasileiros, é imperioso que se proponha outra ideia de cidadania, ou como afirmou Dantas, uma cidadania nova e ressignificada - com novos e diferenciados processos e instrumentos para o seu exercício - baseada no alargamento da ideia de vínculos sociais, culturais, jurídicos e políticos de pertença concomitante às suas sociedades e culturas particulares e ao Estado. Nessa perspectiva, é preciso que o Estado se reconheça como plurinacional e multicultural para que os direitos diferenciados próprios à cidadania indígena sejam efetivos, tanto no âmbito individual e coletivo das pessoas quanto no de organização institucional complexa dos âmbitos públicos Estatais. Sem esse "autorreconhecimento", bem como sem a superação daquilo que Souza Santos e Meneses (2009) determinam pensamento abissal, correremos o risco de apenas constitucionalizar e não efetivar o direito à diferença.

\section{Referências}

ARENDT, Hanna. Origens do Totalitarismo. Rio de Janeiro: Paz e Terra, 1974.

BELLAMY, Richard. Pluralism and Liberal Neutrality. London: Routledge, 1996.

BENEDICT, Ruth. Patterns of culture. Cambridge, Massachussets: Cambridge University Press, 1985.

sentido, ver: Carbonell (2010, p. 207-225). 
BENHABIB, Seyla. Situating the self: gender, community and postmodernism in contemporary Ethics. London/New York: Routledge, 1992.

BRASIL. Constituição. República Federativa do Brasil de 1988. Brasília, DF: Senado Federal, 1988. Disponível em: < http://www2.planalto.gov.br/acervo/constituicao-federal $>$. Acesso em: 20 jan. 2013.

BRASIL. Tribunal Superior Eleitoral. Eleitor: do alistamento ao voto. Brasília: SGI/ Cojur, 2007.

CANCLINI, Néstor García. As culturas populares e o capitalismo. Buenos Aires: Paidós, 1996.

CANCLINI, Néstor García. La globalización imaginada. Buenos Aires: Paidós, 1999.

CARBONELL, Miguel. Desafíos del nuevo constitucionalismo en América Latina. In: CARBONEL, Miguel. Neoconstitucionalismo y derechos fundamentales. Colombia, 2010 .

CAWS, Peter. Identity: Cultural, Transcultural and Multicultural. In: GOLDBERG, David (Org). Multiculturalism: a critic reader. Cambridge: Blackwell Publishers, 1995.

CHARVET, John. The possibility of a cosmopolitan ethical order based on the idea of universal human rights. Millennium, Journal of international studies, v. 27, n. 3, p. 523-542, 1998.

DALLARI, Dalmo de Abreu. Índios, cidadania e direitos. In: COMISSÃO PRÓ-ÍNDIO. O índio e a cidadania. São Paulo: Brasiliense, 1983.DANTAS, Fernando Antonio de Carvalho. Multiculturalismo, cidadania e direito dos povos indígenas. Revista Amazônia Legal, 2012. Prelo.

DANTAS, Fernando Antonio de Carvalho. Relatório de Identificação da terra indígena Guarani-Mbyá da Ilha da Cotinga. Curitiba: FUNAI, 1989.

DE LUCAS, Javier. La sociedad multicultural: problemas jurídicos y políticos. In: AÑON, María José et al. Derecho y sociedad. Valencia: Tirant de Blanch, 1998.

DHABOUR, Omar. The Ethics of Self-Determination: democratic, national and regional. Pstcolonial Studies, v. 4, n. 1, p. 3-20, 1998.

FARIÑAS DULCE, Maria José. Globalización, ciudananía y derechos humanos. Madrid: Dinkinson/Instituto de Derechos Humanos Bartolomé de las Casas/Universidad Carlos III de Madrid, 2000.

FORNET-BETANCOURT, Raúl. Transformación intercultural de la filosofía. Bilbao: Desclée de Brouwer, 2001. 
FUNDAÇÃO NACIONAL DO ÍNDIO. Legislação, Jurisprudência Indígenas. 1983.

GADAMER, Hans George. Verdad y Método. Salamanca: Ediciones Sígueme, 1977.

GHAI, Anna. Neutrality and Recognition. In: BELLAMY, Richard. Pluralism and Liberal Neutrality. London: Portland, 2003.

GOLD. Carol. Two concepts of universality and the problem of cultural relativism. Pstcolonial Studies, v. 4, n. 1, p. 67-83, 2000.

GUIMARÃES, Carlos. El constitucionalismo Cultural. Madri: Boch, 2003.

HÄBERLE, Peter. Pluralismo y Constitución: estudios de Teoría Constitucional de la sociedad abierta. Madrid: Tecnos, 2002.

HERRERA FLORES, Joaquín; RODRÍGUEZ PRIETO, Rafael. Hacía la nueva ciudadanía: consecuencias del uso de una metodología relacional en la reflexión sobre la democracia. Crítica Jurídica: Revista latinoamericana de política, filosofia e direito, n. 17, ago. 2000.

HERRERA FLORES, Joaquín. Las lagunas de la ideología liberal. In: HERRERA FLORES, Joaquín (Org.) El vuelo de Anteo: derechos humanos y crítica de la razón liberal. Bilbao: Desclée de Brouwer, 2000.

KYMLICKA, Will. Liberalism, Community and Culture. Oxford: Oxford University Press, 1989.

KYMLICKA, Will. Multicultural Citzenship: a liberal theory of minority rights. Oxford: Oxford University Press, 2000.

LACLAU, Ernesto. Emacipación y diferencia. Barcelona: Ariel, 1996.

MALIK, Kenan. Universalism and difference in discourses of race. Cambridge: Cambridge University Press, 2001.

MARSHALL, Thomas Humprey. Cidadania, classe social e status. Rio de Janeiro: Zahar, 1963.

MERLE, Jean-Christophe. Cultural Minority Rights and the Rights of the Majority in the Liberal State. Oxford: Blacwell Publishers, 1998.

MODOOD, Tariq. Multiculturalism, Secularism and the State. In: BELLAMY, Richard. Pluralism and Liberal Neutrality. London: Portland, 1996.

MOUFFE, Chantal. The return of the political. Londres: Verso, 1993. 
OLIVEIRA, Roberto Cardoso de. Sobre o diálogo intolerante. In: GRUPIONI, Luís Donizete Benzi. Povos indígenas e tolerância: construindo práticas de respeito e solidariedade. São Paulo: Edusp, 2001.

PALAFOX, Francisco Ibarra. Constitutionalism and citizenship: facing the multicultural challenge. Instituto de investigaciones juridicias, Unam, v. 4, n. 1, p. 59-77.

PANIKKAR, Raimundo. Sobre el dialogo intercultural. Salamanca: Editorial San Esteban, 1990.

PAOLI, Maria Célia Pinheiro Machado. O sentido histórico da noção de cidadania no Brasil: onde ficam os índios? In: COMISSÃO PRÓ-ÍNDIO. O índio e a cidadania. São Paulo: Brasiliense, 1983.

PÉREZ LUÑO, Antonio Enrique. Diez tesis sobre la titularidad de los derechos humanos. In, ROIG, Francisco Javier Ansuátegui (Org.). Una discusión sobre derechos colectivos. Madrid: Instituto de Derechos Humanos Bartolomé de las Casas/Universidad Carlos III, 2002.

PIOVESAN, Flávia. Direitos humanos e o direito constitucional internacional. 5. ed. São Paulo: Max Limonad, 2002.

RIBEIRO, Berta. O índio na história do Brasil. São Paulo: Global Editora, 1987.

RAZ, Joseph. Multiculturalism. Oxford: Blackwell Publishers, 1998.

RODRIGUES, Saulo Tarso. O Direito Internacional dos Direitos Humanos e a Racionalidade Ocidental (Razão Indolente): a epistemologia e a Política Ocidental no Novo Modelo Hegemônico de Democracia (governação) Global. In: RODRIGUES, Saulo Tarso. Direito em Debate: em busca de alternativas. Ijuí: Editora Unijuí, n. 21, p. 91-109, jan./jun. 2004.

RODRIGUES, Saulo Tarso. O modelo de racionalidade ocidental (razão indolente) e os direitos humanos: uma crítica ao conceito hegemônico de cidadania a partir da Sociologia das Ausências de Boaventura de Sousa Santos. Revista do Semiedu, Cuiabá: Universidade Federal de Mato Grosso, 2006.

RODRIGUES, Saulo Tarso. O paradigma da modernidade a problemática dos direitos humanos: Os limites teóricos entre universalismo, multiculturalismo e relativismo cultural a partir da filosofia jusnaturalista e do princípio da dignidade humana. Sanches, 2012.

SÁNCHEZ RUBIO, David. Universalismo de confluencia, derechos humanos y inversión. In: HERRERA FLORES, Joaquín (Org.). El vuelo de Anteo: derechos humanos y crítica de la razón liberal. Bilbao: Desclée de Brouwer, 2000. 
SARTORI, Giovanni. La sociedad multiétnica. Pluralismo, multiculturalismo e extranjeros. Madrid: Taurus, 2001.

SIECKMAN, Jan. Cultural Pluralism and the Ideia of Human Rigths. In: SOETEMAN, Arend. Pluralism and Law. London: Kluwer Academic Publishers, 2001.

SOUSA SANTOS, Boaventura de. A gramática do Tempo. Para uma nova cultura política. Coimbra: Cortez, 2011.

SOUSA SANTOS, Boaventura de. O Estado heterogêneo e o Pluralismo Jurídico. In: SANTOS, Boaventura de Sousa; TRINDADE, João Carlos (Org.). Conflito $e$ transformação social: uma paisagem das justiças em Moçambique. Porto: Afrontamento, 2001.

SOUSA SANTOS, Boaventura de. Para ampliar o canône da diferença e da igualdade. In: Santos, Boaventura de Sousa (Org). Reconhecer para libertar: os caminhos do cosmopolitismo multicultural. Rio de Janeiro: Civilização brasileira, 2003.

SOUSA SANTOS, Boaventura de. Para uma sociologia das ausências e uma sociologia das emergências. In: SOUSA SANTOS, Boaventura de (Org.) Conhecimento prudente para uma vida decente: um discurso sobre as ciências revisitado. Porto: Afrontamento, 2003.

SOUSA SANTOS, Boaventura de. Una concepción multicultural de los Derechos Humanos. Revista Memória, Bogotá, n. 101, jul. 2003.

SOUSA SANTOS, Boaventura de; MENESES, Maia Paula G. (Org.). Epistemologias do sul. Coimbra: Almedina, 2009.

SOUSA SANTOS, Boaventura de. La reinvención del Estado y el Estado plurinacional. Santa Cruz de la Sierra: Alianza Interinstitucional CESNDA-CEJIS-CEDIB, 2007.

SOUSA SANTOS, Boaventura de. La globalización del derecho: los nuevos caminhos de la regulación y la emancipación. Bogotá: Universidad Nacional de Colombia, ILSA, 1998.

SOUZA FILHO, Carlos Frederico Marés de. A cidadania e os índios. In: COMISSÃO PRÓ-ÍNDIO. O índio e a cidadania. São Paulo: Brasiliense, 1983.

SOUZA FILHO, Carlos Frederico Marés de. Multiculturalismo e direitos coletivos. In: SOUSA SANTOS, Boaventura de. Reconhecer para Libertar. Os caminhos do cosmopolitismo multicultural. Rio de Janeiro: Civilização Brasileira, 2003.

SOUZA FILHO, Carlos Frederico Marés de. O renascer dos povos para o Direito. Curitiba: Juruá, 1998. 
SOUZA, Laura de Mello. O diabo e a terra de Sta. Cruz. Feitiçaria e religiosidade no Brasil colonial. São Paulo: Companhia das Letras, 1986.

SOUZA, Maria Tereza Sadek R. de. Os índios e os "custos" da cidadania. In: COMISSÃO PRÓ-ÍNDIO. O índio e a cidadania. São Paulo: Brasiliense, 1983.

TAYLOR, Charles. Growth, Legitimacy and the Modern Identity. Cambridge: Cambridge University, 1981.

TAYLOR, Charles. Philosophy and the Human Sciences. Cambridge: Cambridge University, 1985.

TAYLOR, Charles. The Politics of Recognition. In: GOLDBERG, David (Org). Multiculturalism: a critic reader. Cambridge: Blackwell Publishers, 1995.

TILLEY, John. The Problem for Normative Cultural Relativism. Oxford: Blackwell Publishers, 1998.

TOMMASINO, Kimiye. Os Kaingang da Bacia do Tibagi e suas relações com as terras baixas. Relatório parcial de pesquisa sem maiores dados. Londrina: [s. n.], 1998.

TULLY, James. Strange Multiplicity: constitutionalism in the age of diversity. Cambridge: Cambridge University Press, 1995.

URIBE, Maria Teresa. Emancipação social em um contexto de guerra prolongada: o caso da comunidade de Paz de San José de Apartadó, Colômbia. In: SOUSA SANTOS, Boaventura de (Org.). Democratizar a Democracia. Os caminhos da democracia participativa. Porto: Afrontamento, 2003.

WIEVIORKA, Michel. A Diferença. Lisboa: Fenda Edições, 2002.

YOUNG, Iris Marion. La justicia y la politica de la diferencia. Madrid: Ediciones Cátedra, 2000.

Recebido em: 23 de agosto de 2014 Avaliado em: 19 de novembro de 2014 (Avaliador A) Avaliado em: 04 de dezembro de 2014 (Avaliador B) Aceito em: 04 de dezembro de 2014 
